\title{
A FORMAÇÃO DOCENTE: A IMPORTÂNCIA DA PROFICIÊNCIA LÚDICA PARA O DESENVOLVIMENTO DO AUTISMO
}

Rúdia Vieira dos Santos

Prof. Centro Universitário

\section{RESUMO}

A proposta do artigo consiste em dialogar sobre a temática da proficiência do lúdico na formação acadêmica do professor, de modo que, contribua para o desenvolvimento do aluno com transtorno do espectro do autismo (TEA). Tornar-se significativo fundamentar os conhecimentos sobre o lúdico na formação do futuro professor, pelo fato de acarretar saberes pertinentes para articular aos desafios enfrentados pelos professores em seu cotidiano escolar, tais como: a prática pedagógica, a política e o social da escolarização dos autistas. Sendo capaz de considerar o lúdico uma barreira às práticas pedagógicas aos que se baseiam numa teoria clássica, onde se pode notar claramente que as estratégias metodológicas clássicas é que são limitadas. Uma das missões da instituição de ensino superior consiste em oferecer condições propícias para desenvolver habilidades, competências e qualificar o profissional para o pleno exercício de suas funções educativas. Os saberes provenientes da formação inicial proporcionam a base para diferenciar as teorias metodológicas, sendo que, a construção deste conhecimento é relevante para o campo de atuação dos futuros docentes. Esta obra tem como objetivo elucidar a importância do lúdico para a formação do professor cuja contribuição consiste na prática lúdica um recurso pedagógico facilitador para o amplo desenvolvimento do educando autista.

Palavras-chave: Lúdico, Autismo, Prática docente, Formação docente 


\section{ABSTRACT}

This article aims to discuss the topic of playful proficiency in the academic education of the teacher which contributes to the development of students with autism spectrum disorder - ASD. It explores becoming meaningful in the knowledge of playfulness in the development of the future teacher. It brings pertinent knowledge to articulate the challenges faced by teachers in their school routine such as the pedagogical, political and social practices of schooling for autistic children. It explains how to be able to deal with barriers in the pedagogical practices that are based on traditional theory, which shows that its methodological strategies are limited. The mission for the higher education institution is to offer favorable conditions to develop skills, competences and qualify the professional for the full exercise of their educational functions. The knowledge from initial training provides the basis for differentiating methodological theories and the construction of this knowledge is relevant to the field of action of future teachers. This article objective is to elucidate the importance of the ludic formation of the teacher whose contribution consists of the ludic practice and pedagogical resource that facilitates the ample development of the autistic student.

\section{Key-words: ludic, autism, teaching practice, teacher training}

\section{1- INTRODUÇÃO}

É necessário analisar a política educacional com criticidade devido abrangência de sua ação, isto é, um pensamento reflexivo sobre essa ação onde envolve muitos atores e diferentes interesses sendo que estes mudam as ações, as concepções e a cultura gerada nas diferentes relações que transpassam pelo processo de formação do professor e pelas práticas de ensino.

A Política Educacional é composta por um conjunto de leis que visa melhorar a educação de uma nação, sua influência interfere nas estruturas formativas e informativas desta forma reestrutura a sociedade. E conta com a participação das esferas da União, Distrito Federal, o Estado e os Municípios, onde cada uma dessas esferas podem elaborar leis com os devidos fins para atender o meio social, desde que, tendo como base a Lei suprema a Constituição Federal do Brasil de 88 também tem o eixo norteador da Lei de Diretrizes e Bases da Educação que regulariza e organiza o sistema educacional tanto público quanto privado e, determina a titulação específica da formação docente em nível médio e superior assim comprimindo as exigências perante lei para sua futura atuação.

Depois de sancionada a Lei n.o 13.977/2020, cria a Carteira de identificação da Pessoa com transtorno do Espectro do Autismo com objetivo de assegurar atenção integral e 
priorizar o atendimento nos diferentes seguimentos, com essa medida altera a Lei Federal n.. 12.764/2012, o texto aborda a proteção dos direitos da pessoa com transtorno do espectro do autismo, descreve a característica comportamental do indivíduo com autismo, apresenta às diretrizes que devem ser cumpridas e respeitadas inclusive o acompanhamento de uma equipe multiprofissional, a prioridade no atendimento médico à pessoa com autismo, no que diz respeito à Educação deve promover atendimento educacional especializado quando comprovado o autista tem o direito a um assistente, sem dúvida foram medidas importantes para efetivar o direito das pessoas com espectro do autismo.

Na sequência, o destaque consiste na formação do professor esta base solidifica as estruturas cognitivas para assim construir o domínio sobre os conhecimentos teóricos que na subsequência será confrontado com a prática pedagógica. Neste contexto, sobre a importância do conhecimento não podemos descartar os conhecimentos prévios do sujeito enquanto aluno ocupante de uma cadeira universitária, pois o seu saber também é significativo, mas cabe refletir sempre sobre as mudanças sofridas pela sociedade contemporânea, a legislação vigente, estes saberes são pertinentes e resultam numa formação de qualidade, ao passo que desmorona o conhecimento ultrapassado e constrói um novo conhecimento.

Deveras, outro conhecimento que também é importante para o campo de atuação do professor e o conhecimento do lúdico. A cultura lúdica passasse assumir uma postura na prática pedagógica que propicia momentos de ensinar e aprender brincando, com isso, o sujeito que ensina precisa estar inteirado do conhecimento para alcançar o êxito com as práticas lúdicas assim contribuir no desenvolvimento das potencialidades e habilidade no educando com autismo. Essas ações, em conjunto, considerando o aluno como um ser singular e suas peculiaridades necessitam ser motivadas ainda que não seja uma tarefa fácil para o educador, contudo, a ludicidade inserida no ambiente escolar contribuir por favorecer o aprendizado do autista.

Com intuito de refletir sobre a importância da formação do professor na qual encontrarse a possibilidade do docente tornar-se naquele que se apodera do conhecimento pertinente à sua qualificação profissional, consequentemente, reflete no campo de atuação e as diversas situações de ensino e aprendizagem. Evidentemente, que o professor vai precisar compreender que cada autista é um autista, entender essa singularidade humana observar que a disfunção cognitiva e comportamental pode receber os estímulos que propicie qualidade no momento de executar a ludicidade.

\section{2- A FORMAÇÃO DOCENTE NO CONTEXTO POLÍTICO}

Ao falar sobre Política, pode-se percorrer um caminho extenso que nos levará por muitos outros caminhos. No entanto, este artigo compete conhecer a Política da arte do saber da Educação, ainda assim, por ser um assunto abrangente exige da pesquisadora 
uma seleção das principais leis educacionais vigentes que são pertinentes ao tema proposto nesta pesquisa científica.

Primeiramente, cabe salientar que, a Lei de Diretrizes e Bases da Educação Nacional LDB n. 9.394/96, em seu Art. n.o 61, denomina o profissional habilitado à licenciatura para atuação na Educação Básica todo sujeito com a formação em nível médio e superior. O primeiro destina-se ao diploma com o título de Magistério são aulas direcionadas à Educação Infantil, o segundo refere-se ao nível superior designado à Educação Infantil, Ensino Fundamental e Médio com os respectivos títulos denominados pelas Licenciaturas em Pedagogia, Língua Portuguesa, Matemática, História, Geografia e etc., conforme determinado pela legislação recebe a definição de trabalhadores da

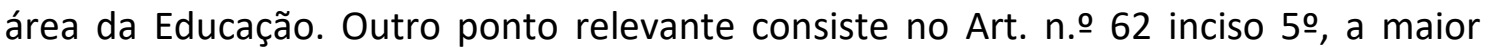
colaboração entre a União, o Distrito Federal, os Estados e os Municípios incumbidos de incentivar o profissional diplomado de Magistério para progredir em seus estudos, onde os órgãos competentes devem fornecer programas de estudo de iniciação aos estudos em nível universitário.

Em seu caráter norteador, a intencionalidade da proposta da LDB voltado às instituições de ensino superior pública ou particular que oferte o curso de formação de professor, deve incluir no currículo os conhecimentos pertinentes a Base Nacional Comum Curricular - BNCC. No entanto, não somente a LDB, possuir o poder de mudar a realidade educacional, contudo, vale analisar que temos outras políticas que também regem a educação brasileira como a Constituição Federal e o Plano Nacional de Educação - PNL entre outras que do mesmo modo acaba por evidenciar ausência na articulação atrelada à qualidade da educação.

Na perspectiva da práxis na formação do professor para Educação Básica, o Plano Nacional de Educação para o decênio de 2014 - 2024, que estabelece na Meta 15 mediante estratégia 15.8, cuja definição consiste em valorizar as práticas de ensino nos cursos de formação para o nível médio e superior dos profissionais da educação, com objetivo de sistematizar e articular o fazer pedagógico proporcionado na formação acadêmica frente às exigências da educação básica (BRASIL, PNE, 2014). É notório que, no Brasil, o desafio consiste em viabilizar uma educação integrada devido à ausência em articular as diferentes políticas públicas, sendo elas, o poder supremo da Constituição Federal de 1998, juntamente com a LDB e o Plano Nacional de Educação (GISSI, BUCCIO, 2015).

Vejamos, temos um conjunto de políticas que regem a ação do professor e refletir sobre esse complexo entrelaçamento de influencias, tendo em observância que essa construção é regida por diversos atores e interesses para formação de uma determinada sociedade, ou seja, num contraste de luta por poderes, onde designa compreender essa 
multiplicidade e a complexidade do que há compõe para se chegar numa concepção que a política docente é entendida por quem a constituir (TELLO e MAINARDES, 2015, p. 44).

Com base nessas estruturas ainda que de maneira reducionista chegar-se a compreender que o Estado enquanto autoridade legal esteja a serviço da classe dominante. Sendo que, na realidade deveríamos entender $o$ Estado como uma instituição regida pela lei, sobretudo a serviço de todos os segmentos sociais (ALMEIDA e TELLO, 2015, p. 185).

Logo, percebe-se que os autores apontam setas com maior centralidade nas tomadas de decisões em relação ao cargo exercido pelo professor, cabe observar que temos políticas educacionais que determina o salário, carga horária, condições de trabalho, plano de carreira, esses pontos relevantes para profissão acaba por sofrer modificações devido ao modo que ocorre à organização mundial de produção política e econômica, movidas pelo capitalismo e, desta forma, sim, produz novas formas culturais, tecnológicas e educacionais.

Contudo, toda essa trajetória política visa proporcionar as devidas mudanças para melhorar a educação nacional nos diferentes aspectos: o acesso e a permanência, qualificação profissional preparo para formação acadêmica, inicial e continua para uma ação que propicie integração, socialização e inclusão nas diferentes modalidades da educação básica, incluindo a educação especial. Neste contexto, das políticas docentes, destaca o engajamento da Associação Nacional de Pós Graduação e Pesquisa em Educação - ANPED; Associação Nacional de Política e Administração Escolar - ANFOPE; Associação Nacional Pela Formação dos Profissionais da Educação - ANPAE; Centro de Estudos Educação e Sociedade - GEDES, com efeito, movidas pela preocupação com os moldes oferecidos nos cursos de formação docente buscam interagir por meio de diálogo e acompanhamento as determinações estabelecidas pela política para os cursos de licenciatura no Brasil.

É apropriado analisar a política docente sob uma ótica crítica da atual realidade, no mesmo seguimento deixa perceptível que sem essas ações políticas não teríamos as mudanças mesmo que ainda não tenha alcançado a satisfação dos profissionais da Educação e a plena qualificação da formação acadêmica.

A educação num contexto de formação inicial ou contínua não pode negligenciar-se motivada pela cegueira sobre os conhecimentos autísticos, isto é, cabe inteirar-se sobre a política que institui medidas de proteção dos direitos dos indivíduos com espectro do autismo, conforme sancionado pela Lei n.o 12.764, de 27 de Dezembro de 2012, certamente foi um marco devido iniciativa de ação política por efetivar e legislar em prol da educação inclusiva brasileira. 
Art. 10 Instaura a Política Nacional de Proteção dos Direitos da Pessoa com Transtorno do Espectro do Autismo, que estabelece diretrizes para serem cumpridas.

$\S 1$. P Para os efeitos desta lei, é considerada pessoa com TEA aquela portadora de síndrome clínica caracterizada na forma dos seguintes incisos I e II.

I - Deficiência persistente e clinicamente significativa da comunicação e na interação social, manifestada por deficiência marcada de comunicação verbal e não verbal usada para interação social; ausência de reciprocidade social; falência em desenvolver e manter relações apropriadas ao seu nível de desenvolvimento;

II - Padrões restritivos e repetitivos de comportamentos, interesses e atividades, manifestados por comportamentos motores ou verbais estereotipados ou por comportamentos sensoriais incomuns; excessiva aderência a rotinas e padrões de comportamentos ritualizados; interesses restritivos e fixos.

$[\ldots]$

Desta forma, os incisos I e II permitem ao professor uma amplitude em relação às manifestações apresentadas pelos alunos no ambiente escolar e deixa claro que o autista possui direitos que são protegidos por lei. Foi acrescido o § 3 ㅇ incluído pela Lei 13.977/2020, que diz respeito aos estabelecimentos públicos e privados para mostrar consciência e priorizar o atendimento com o uso do símbolo mundial do Autismo a fita quebra-cabeça.

Art. 20 Descreve as Diretrizes da Política Nacional de Proteção dos Direitos da Pessoa com Transtorno do Espectro do Autismo é composto por oitos incisos exceto o quarto que foi vetado, o conteúdo orienta sobre a importância da participação da comunidade na formulação de políticas públicas; atenção integral às necessidades de saúde com atendimento multiprofissional ao acesso dos medicamentos e nutrientes em especial o diagnóstico precoce; o estímulo à inserção da pessoa com autismo no mercado de trabalho; o poder público esta incumbido de tornar público às informações relativas ao transtorno e suas implicações; incentivo para pais e responsáveis e os profissionais especializados em buscar capacitação para o atendimento à pessoa com autismo; incentivo à pesquisa científica realizada no território brasileiro com estudos epidemiológicos das pessoas com autismo.

Art. 30 Descreve os direitos dos autistas que devem ser respeitados e acatados por todos.

I - A dignidade, a integridade física e moral, o livre desenvolvimento da personalidade, a segurança e o lazer;

II - A proteção contra qualquer tipo de abuso e exploração; 
III - o acesso a ações e serviços de saúde, com vistas à atenção integral às suas necessidades de saúde, tais como: o diagnóstico precoce mesmo que não seja o definitivo; atendimento multiprofissional; a nutrição adequada e a terapia nutricional; os medicamentos; informações que auxiliem no diagnóstico e no tratamento.

IV - o acesso garantido à educação e ao ensino profissionalizante; à moradia, inclusive tendo sua residência protegida; ao mercado de trabalho; à previdência social e à assistência social.

Parágrafo único: caso seja comprovada necessidade do educando com espectro do autismo inserido na classe regular do ensino regular, dentro dos termos do inciso IV do art. 2으, terá direito a um acompanhante.

Art. 3--A. É criada a Carteira de identificação da Pessoa com transtorno do Espectro do Autismo (Ciptea), com objetivo garantir atenção integral e priorizar o atendimento e o acesso aos serviços públicos e privados, em especial nas áreas de saúde e educação e assistência social. (Incluído pela Lei n.o 13.977, de 2020).

$\S 1$ 10 A Ciptea será expedida pelos órgãos responsáveis pela execução da Política Nacional de Proteção dos Direitos da Pessoa com Transtorno do Espectro Autista, do Distrito Federal e dos Municípios, mediante requerimento, acompanhado de relatório médico, com indicação do código da Classificação Estatística Internacional de Doenças e Problemas Relacionados à Saúde (CID).

Na Carteira de identificação do autista deve conter seus dados pessoais, tais como: uma foto $(3 \times 4)$, nome completo, filiação, local e data de nascimento, número da carteira de identidade civil, número de inscrição no Cadastro de Pessoas Físicas (CPF), tipo sanguíneo, endereço residencial completo e número de telefone do identificado, assinatura ou impressão digital do identificado, como também, os dados pessoais do responsável legal ou do cuidador nome completo, documento de identificação, endereço residencial, telefone e e-mail, para comprovar a veracidade será necessário identificação da unidade da Federação e do órgão expedidor e assinatura do dirigente responsável. (Incluído pela Lei n.ㅇ 13.977, de 2020).

$\S 2$ Q Quando o autista for estrangeiro e estiver com visto temporário ou autorização de residência, residente fronteiriço ou solicitante de refúgio vai precisar apresentar a Cédula de Identidade de Estrangeiro (CIE), a Carteira de Registro Nacional Migratório (CRNM) ou o Documento Provisório de Registro Nacional Migratório (DPRNM), com validade em todo o território nacional. (Incluído pela Lei n.o 13.977, de 2020).

§ 3으 A Ciptea terá validade de 5 (cinco) anos e qualquer alteração nos dados pessoais será necessário atualizar, devido emissão da carteira de identificação possibilita a 
contagem das pessoas com espectro do autismo em território brasileiro. (Incluído pela Lei n.o 13.977, de 2020).

$[\ldots]$

Art. 4ํ A pessoa com transtorno do autismo não será submetida a tratamento desumano ou degradante, não será privada de sua liberdade ou do convívio familiar nem sofrerá discriminação por motivo da deficiência.

Parágrafo único: Caso seja necessário intervenção médica em unidades especializadas basta consultar o art.4ㅇ da Lei n. 10.216, de 6 de abril de 2001.

Art. 5을 Assegura a pessoa com autismo de participar em planos de assistência à saúde sem discriminar sua condição de deficiente, com forme dispõe o art. 14 da Lei n.o 9.656, de 3 de junho de 1998.

Art. 60 (Vetado)

Art. 70 O gestor escolar não poderá recusar a matrícula de pessoas com autismo na Instituição de Ensino, caso isso ocorre será punido com multa de 3 (três) a 20 (vinte) salários-mínimos.

$\S 1$ 으 Em caso de reincidência será apurado mediante processo administrativo, no caso comprovação, haverá a perda do cargo.

$\S 2$ (VETADO).

Art. 8을 Esta Lei entrou em vigor na data de sua publicação.

Brasília, 27 de dezembro de 2012, 191ㅇ da Independência e 124ㅇ da República.

\section{DILMA ROUSSEFF}

José Henrique Paim Fernandes

Mirian Belchior

Se existisse uma receita pronta para a Educação, iria começar na formação do professor, na sua capacitação, na grandeza de seu ofício. Sendo assim, no âmbito dos saberes pedagógicos, buscar a excelência à formação e a capacitação de profissionais especializados para atender educandos com espectro do autismo, como também, receber assistência da gestão democrática estruturada num projeto emancipador que visa o trabalho coletivo e interdisciplinar onde o protagonista do conhecimento é o aluno com TEA. 


\section{3 - A FORMAÇÃO INICIAL UM PROCESSO DE APERFEIÇOAMENTO}

Quando um indivíduo decide escolher pelo campo da educação espera-se que seja consciente e com amorosidade, um momento para sentir-se contemplado pela decisão de ser um professor, cuja primeira lembrança e experiência de sala de aula fora na escola primária. O autor Camargo (2010), afirmar que quanto mais significativo for o professor, melhores serão as oportunidades para promover novas aprendizagens para seus alunos, com isso, pode-se destacar que é indubitável a importância da graduação para o sujeito que deseja exercer a profissão de docente e, nesta fase de ascensão profissional buscase pelos saberes provenientes da formação inicial.

Saberes dos Professores ${ }^{1}$ :

\begin{tabular}{|c|c|c|}
\hline Saberes dos Professores & Fontes sociais de aquisição & $\begin{array}{c}\text { Modos de integração de } \\
\text { interação no trabalho } \\
\text { docente. }\end{array}$ \\
\hline $\begin{array}{c}\text { Saberes pessoais dos } \\
\text { professores }\end{array}$ & $\begin{array}{c}\text { A família, o ambiente de } \\
\text { vida, a educação no sentido } \\
\text { lato etc. }\end{array}$ & $\begin{array}{c}\text { Pela história de vida e pela } \\
\text { socialização primária }\end{array}$ \\
\hline $\begin{array}{c}\text { Saberes provenientes da } \\
\text { formação escolar }\end{array}$ & $\begin{array}{c}\text { A escola primária e } \\
\text { secundária, os estudos pós- } \\
\text { secundários não } \\
\text { especializados etc. }\end{array}$ & $\begin{array}{c}\text { Pela formação e pela } \\
\text { socialização pré- } \\
\text { profissionais }\end{array}$ \\
\hline $\begin{array}{c}\text { Saberes provenientes da } \\
\text { formação profissional }\end{array}$ & $\begin{array}{c}\text { Os estabelecimentos de } \\
\text { formação de professores, os } \\
\text { estágios, os cursos de } \\
\text { reciclagem etc. }\end{array}$ & $\begin{array}{c}\text { Pela formação e pela } \\
\text { socialização profissional nas } \\
\text { instituições de formação de } \\
\text { professores }\end{array}$ \\
\hline $\begin{array}{c}\text { Saberes provenientes dos } \\
\text { programas e livros } \\
\text { didáticos usados no } \\
\text { trabalho }\end{array}$ & $\begin{array}{c}\text { O uso de "ferramentas" dos } \\
\text { professores, programas, } \\
\text { livros didáticos, cadernos de } \\
\text { exercícios, fichas etc. }\end{array}$ & $\begin{array}{c}\text { Pelo uso das "ferramentas" } \\
\text { de trabalho, sua adaptação } \\
\text { às tarefas }\end{array}$ \\
\hline $\begin{array}{c}\text { Saberes provenientes de } \\
\text { sua própria experiência } \\
\text { na profissão, na sala de } \\
\text { aula e na escola }\end{array}$ & $\begin{array}{c}\text { A prática do ofício na escola } \\
\text { e na sala de aula, a } \\
\text { experiência dos pares etc. }\end{array}$ & $\begin{array}{c}\text { Pela prática do trabalho e } \\
\text { pela socialização profissional }\end{array}$ \\
\hline
\end{tabular}

${ }^{1}$ CUNHA, Eugênio. Autismo na escola: um jeito diferente de aprender, um jeito diferente de ensinar. 5a ed. Rio de Janeiro, 2018 , p. 45.

E na realidade o conhecimento do professor transcende os saberes provenientes de sua formação inicial, também se acrescentam suas próprias emoções, a cognição, as expectativas e a história pessoal. Neste sentido, tornar-se complexo separar o ser e o fazer além do mais todos passamos pelo dinamismo das transformações sociais, não ha como ignorar, que essas ações também são inseridas no trabalho pedagógico, deve-se analisar que o educador de hoje foi o educando de ontem são inúmeras as influencias que leva este profissional até a sala de aula. O professor ao adentrar na sala de aula 
carrega consigo seu contexto histórico social e, nele está inserido uma somatória de características tais como: suas crenças, os modelos dos professores do tempo da escola, do período da universidade, a própria concepção mediante as lembranças sobre o que é ser um bom professor e como é ser um aluno. Por isso, notar-se o quanto é importante o processo de construção do saber do docente corroborar uma boa fundamentação teórica para subsidiar a prática educativa, neste contexto, o lúdico tem papel fundamental na formação acadêmica sendo possível realizar as devidas intervenções nos alunos autistas, posto que, o professor também possui um papel fundamental na educação inclusiva (ANDRÉ, 2010; TARDIF, 2012; CUNHA 2018).

Necessário que os futuros educadores possam, verdadeiramente, utilizar de maneira adequada e explorar toda a capacidade da ludicidade inicialmente proporcionada na formação acadêmica, respectivamente preparar e oportunizar, inclusive, atividades práticas em que possam evidenciar claramente o poder deste recurso metodológico, sendo que, para ensinar de modo lúdico o mediador precisa compreender a importância dessa prática pedagógica. O lúdico tem o poderio de atuar de maneira leve e prazerosa, destaca-se por ser um mecanismo pedagógico facilitador que propicia a construção de saberes significativos à formação do aluno de maneira que permite contribuir e enriquecer o trabalho do docente.

O autor Cunha (2018) faz uma crítica à visão da formação do professor por ser instruída de modo diferenciado e fragmentado, justamente pela observação de encontramos professores em âmbito federal, estadual e municipal, temos educadores lecionando na rede pública e no particular, em cidades urbanas e rurais e professores titulados e não titulados, certamente, abre-se espaços para conflitos e desafios provenientes das mudanças sociais e a prática pedagógica em ambientes escolares. Gatti (2010) ressalta a crítica causada pela fragmentação formativa e, complementa que é necessário reestruturar os currículos das instituições de ensino superior com o intuito de articular o conhecimento teórico pertinente ao campo das disciplinas com a experiência do cotidiano escolar, ou seja, proporcionar um ensino aos futuros educadores que contemple os saberes congruentes a teoria e a realidade social, sobre o olhar atento ao aluno que é o protagonista da construção do seu conhecimento.

De acordo com Cunha (2018), uma das circunstâncias apresentadas para combater a formação fragmentada é viabilizar políticas públicas, no entanto, a dificuldade encontrada consiste na ausência de apoio político por parte dos governantes. Na busca por articular os conhecimentos pertinentes para qualificar o professor para o campo da prática pedagógica.

Atualmente, temos outra modalidade de ensino à distância que também é considerada como modalidade de educação superior para obter acesso à formação inicial e continuada, juntamente, com essa roupagem tecnológica que propiciar e consolidar o 
EaD no Brasil. FRANCO (1997), o Sistema de Educação à Distância que faz uso da tecnologia inserido no campo do saber da Educação, apresenta perspectiva que permitir um novo olhar nos processos de ensino e aprendizagem onde se estabelece a construção do saber mediados pelas tecnologias digitais de informação e comunicação - TDIC, cuja intenção é capacitar o profissional que assim optar pelo estudo científico mediante uso dos recursos midiáticos, o curso tem como característica oferecer aulas semipresenciais, que promovem encontros semanais ou totalmente à distância por intermédio de Plataforma estudantil, essa experiência em utilizar plataforma propriamente ressignifica as relações do ensinar e do aprender na convencional sala de aula universitária.

Oportunamente, a pesquisa de Barretto (2015), faz uma crítica ao sistema de educação à distância ao passo que descreve a insuficiência na construção do saber e ausência de troca de experiência no contexto da formação do futuro professor, o modelo de formação EaD de pendendo da oferta do curso acaba por reduzir o pragmatismo cuja fundamentação é tão importante para questões mais amplas envolvidas no processo educativo, como também, inviabilizar a realização de práticas pedagógicas que propicie experiências necessárias na relação entre professor e educando com autismo.

Educação à distância possui outra característica à diplomação que sucede por intermédio de uma Faculdade, com isso, o curso em EaD pode deixar em descrédito as condições que viabiliza o docente de experienciar novas habilidades e competências no exercício da profissão nos diferentes espaços escolares. Por sua vez, para realizar os estágios tornar-se necessário que a Instituição de Ensino Superior esteja credenciada nas determinações administrativas da Secretária de Educação, a partir daí, o estudante munido da autorização pode concretizar essa vivência com os alunos autistas nos diferentes ambientes escolares, o que favorece e enriquece a formação acadêmica.

Em vista disso, pensasse em qualificar o professor para adquirir um conjunto de saberes e experiências necessários até mesmo pela complexidade existente no sistema educativo e na educação inclusiva que infelizmente ainda temos educadores que demonstra receio de como fazer para interagir com seus alunos autistas, justamente pela falta de conhecimento e experiência no que diz respeito aos conhecimentos pertinente sobre autismo, logo, percebe-se a importância em ressaltar o período de formação inicial e continuada tornar-se essencial capacitar, treinar e sistematizar esse professor, atribuir para o campo de atuação habilidades e competências para diminuir risco de abandono escolar (IMBERNÓN, 2006; BRITES, 2019).

Uma formação acadêmica que se preocupa em qualificar o futuro docente contém na proposta curricular da universidade não apenas informação teórica como também se alicerça na prática docente, é muito importante transitar esses dois aspectos, a ponto de obter uma formação significativa para assegurar educação inclusiva. Talvez o desafio 
das universidades, não que sejam de todas, no entanto, consiste na dificuldade em incorporar os requisitos no currículo onde tornar-se necessário acompanhar e avaliar sua validação na contribuição da formação do professor. Outra característica indicada pelo Paulo freire (2015), consiste em analisar a formação dos professores e sua práxis pedagógica fazendo menção ao diálogo, sendo este, fundamental para reflexão e o comprometimento com a pedagogia política em assumir uma educação problematizadora, humanizadora e libertadora, afim de, conquistar uma educação emancipadora em prol da consciência de sua existência transformadora inserido na sociedade contemporânea.

\section{4 - A IMPORTÂNCIA DO LÚDICO NA PROFICIÊNCIA DO DOCENTE PARA O DESENVOLVIMENTO DO AUTISTA}

Um ponto relevante para ser abordado é o acervo literário pedagógico voltado à prática na educação especial, essencial para alicerçar a construção do conhecimento do educador especialmente no que se refere à inclusão da criança com o espectro do autismo nos diferentes ambientes escolares. $O$ autor descreve ser o campo da medicina onde mais se explora assuntos relacionados ao autismo, logo, pode-se encontrar com maior facilidade livros na literatura médica, o que prejudica o educador em buscar acervo específico esse conhecimento é pertinente para compreender a necessidade educativa específica voltada à prática pedagógica para dinamizar o ensino e aprendizagem do aluno de inclusão (CUNHA, 2018, p. 48).

No mundo do autismo, um professor competente procura primeiramente entender o aluno com autismo e se permite muito mais aprender com ele, do que propriamente apenas ensinar (BRITES, 2019, p. 140).

Conforme afirmação da citação à cima, quem aprende primeiro é o docente e quem primeiro ensina é o discente desse modo ambos estão interagindo esse é o momento ideal para o professor conhecer o autista, o que faz parte dos seus conhecimentos prévios? O que pode ser significativo para criança a ponto de ser utilizado nas práticas lúdicas, a partir daí, a intervenção pedagógica ganha seu espaço no mundo do autista.

De acordo com Kishimoto (2011), devemos pensar como faremos para harmonizar a relação entre professor e aluno autista, a interação precisa acontecer e gira em torno do protagonista do conhecimento inserido no espaço escolar, analisando sob uma ótica que todo esse conhecimento já foi trabalhado na formação inicial e aprofundado nos cursos de extensão referente às propriedades formativas do jogo, considerada importante para o desenvolvimento da criança e pode ir além de um simples entretenimento basta atribuir ao jogo, o brincar e a brincadeira num contexto de cunho pedagógico. 
O jogo realiza por meio da atuação dos participantes que executam as regras causando a ação lúdica na brincadeira, a partir daí, a brincadeira passa a se tornar coisa séria, inserida numa perspectiva pedagógica sendo utilizada como recurso didático (KISHIMOTO, 2011, p. 189).

Utilizar o lúdico no ambiente escolar não é uma tarefa fácil para o educador, requer clareza, dado que sua aplicabilidade deve ser lúdica e educativa, é muito importante no processo de ensino e aprendizagem cultivar a relação professor/aluno principalmente com a utilização das práticas lúdicas para o desenvolvimento da criança com autismo, refletir que o brincar, a brincadeira, o jogo são recursos metodológicos eficazes, por facilitar o processo de desenvolvimento cognitivo, social e físico. Segundo Vygotsky (2007), o brincar estimula a zona de desenvolvimento proximal, seus estímulos incentiva o aluno a avançar o estágio de desenvolvimento já atingido, mas, cabe ao mediador adequar esse momento para que de fato ocorra a brincadeira. Nesta linha de pensamento Borges (2018), afirma que a brincadeira acompanhada de brinquedo contribuir para o desenvolvimento do autista principalmente quando experienciado junto com os seus pares e não isoladamente, vale destacar que mesmo não sendo fácil essa ação mediadora deve-se atribuir amorosidade e respeito ao proporcionar a ludicidade nos espaços escolares.

$O$ ato de brincar não pode ser resumido apenas em fonte de prazer, e sim o oposto, a criança realiza essa atividade para fazer-se pertencente no universo a sua volta, o saber historicamente construído do mundo da cultura, ou seja, a criança ao brincar vivencia realidades do mundo dos adultos acaba projetando a cultura e estabelecendo futuros papeis $e$ valores (OLIVEIRA, 2007, p. 56).

Nesta concepção deve-se compreender que o papel do professor se torna fundamental proveniente da inclusão escolar propiciar situações que envolva a brincadeira, o jogo e o brincar atribuindo significado para construção histórica e social do aprendiz. Segundo Cunha (2018), os jogos são ótimos estímulos para conhecer limites e regras, perceberse que os momentos de descontração e também os momentos que os alunos estão dialogando sobre as regras da brincadeira ocorre à estimulação da linguagem pela interação, do mesmo modo acontece com o brinquedo, pois meio da interação que ocorre o desenvolvimento de funções sociais que passam pelo processo de maturação.

Cabe ao professor assumir em seu campo de atuação um caráter afetivo, observador, comprometido com a realidade lúdica um recurso metodológico de relevante contribuição em todo o processo do ensino e aprendizagem do educando com autismo. Para dialogar temos Brites (2019), por afirmar que o educador está para o desenvolvimento da criança, com isso, autora denomina outros adjetivos que também classifica o professor, tais como: compreensivo, flexível, com espírito conciliador devido 
às novas realidades enfrentadas pelo autista, o primordial ter a consciência que cada autista é um autista, não cometer o erro de generalizar os comportamentos autísticos.

Pautada na legislação toda criança possui direito de aprender e brincar incluindo as crianças com espectro do autismo. A autora considerar importante e destaca dois tipos de inclusão a escolar e a social, logo, a explicação atribuída sobre a primeira maneira de promover inclusão deve-se colocar em vigor procedimentos para efetivar as regras e as rotinas que são importantes para todas as crianças, mas em especial os autistas com objetivo de desenvolver suas habilidades e potencialidades que são pertinentes para alcançar o êxito nas áreas do conhecimento. A inclusão social aborda a postura do professor-mediador para que o trabalho pedagógico direcione momentos de compartilhar sentimentos e estabelecer diálogo, compreender que essa relação social afeta positivamente os valores de tolerância e paciência significativo e necessário no cotidiano escolar devido enfrentamento dos conflitos em lidar com o diferente e as diferenças em sua amplitude (BRITES, 2019, p. 137).

Isso significa que, a inclusão escolar e institucional dar-se-ia na carência de estruturas que priorize as dificuldades e as particularidades de todos os alunos, aqui em especial o educando com espectro do autismo por demonstrar limitações sensoriais, sensitivas, estereotipias, possui também dificuldades de comunicação verbal e não verbal principalmente se a linguagem do professor não for clara e objetiva, para isso necessário assumir meios de comunicação visuais e auditivos para estabelecer o entendimento do aluno autista. É claro que na inclusão escolar e na social exista semelhança sendo bastante significativa ao passo que os profissionais o gestor, coordenador, os professores, a secretária, o refeitório dentre outros ambientes da escola com primazia precisa obter os conhecimentos sobre o TEA, até mesmo, para aqueles momentos que seja necessário as devidas intervenções, desde que, acontecer de modo adequado (BRITES, 2019, p.143).

Não obstante, de proporcionar ao discente com autismo um ambiente agradável inserindo-o na concepção do lúdico, cuja proposta fundamenta-se no ensinar e no aprender onde o aluno possa se sentir seguro para explorar novas possibilidades, criar conexões, desenvolver novas habilidades, a curiosidade pelo novo, a criatividade e a expressividade. Assim podemos chamar de "aprender brincando" e para isso as brincadeiras são adaptadas de modo que se tornem motivadoras e apropriadas para o autista, quando a criança com TEA sente-se motivada a interagir com o educador, tem a chance de criar interações dinâmicas com outras pessoas e isso auxilia no desenvolvimento de habilidades como contato visual, de linguagem e de conversação.

Ao descrever que os jogos, a brincadeira e o brincar são objetos estruturadores do conhecimento e do saber, pois sua contribuição consiste no manusear do objeto concreto que possibilita as funções cognitivas construir o conhecimento abstrato, de 
modo que, essa experiência tornar-se fundamental para aprendizagem do autista sendo perceptível a passagem do objeto concreto para o objeto construído na aquisição do saber. O lúdico no contexto pedagógico traz algumas acepções a respeito dos jogos, das brincadeiras e do brincar, sua aplicabilidade estimula as múltiplas inteligências e privilegia os eixos cognitivos, mas, pode acontecer que na aplicabilidade da ludicidade utilizando o mesmo recurso chega-se alcançar todas as inteligências, como também, não chega a alcançar todas as inteligências, neste caso cabe analisar que cada autista possuir a sua singularidade, de repente tenha o aluno que acabe exigindo um trabalho mais específico, tirando essa peculiaridade o lúdico continua apresentando seu potencial (ANTUNES, 1998; KISHIMOTO, 2011).

"... Todo jogo pode ser utilizado para qualquer criança, mas seu efeito sobre a inteligência continuará sendo pessoal e impossível de ser generalizado" (ANTUNES, 1998, p. 16).

Sob esse enfoque, o dinâmico processo de construção do conhecimento, tanto quão complexa por esperar ver o docente ensinando e brincando com seus discentes numa relação onde o fator determinante é o processo do conhecimento mediante contribuição do lúdico, em vista disso, fica cada vez mais presente a necessidade de reestruturar o papel do professor como agente atuante na cultura lúdica.

Em suma, aproveitar todas as propostas de aprendizagem que o brincar possa proporcionar, mais uma vez a importância do conhecimento, para chegar ao êxito da estratégia pedagógica inicialmente cabe planejar, adequar, organizar e apresentar os brinquedos ao educando com autismo, dessa forma, tornar-se uma atividade lúdica num aprendizado significativo, para isso o professor deve ter clareza que o intuito é ser lúdico e educativo.

\section{5 - CONSIDERAÇÕES FINAIS}

Em primeiro lugar, cabe salientar que a formação inicial deve ser composta por um conjunto de saberes pertinentes, a fim de, instruir e capacitar um bom profissional para área da Educação pode-se destacar a fundamentação teórica sendo esta essencial à práxis pedagógica, dela se extrai a metodologia pedagógica que vai ao encontro da proposta educativa. A formação inicial e contínua do Professor pode ser comparada ao processo de lapidar um diamante, pelo fato e sem dúvida nenhuma é uma profissão a ser admirada, qualificada e respeitada.

Enfatizo que a característica fundamental do lúdico consiste em oferecer práticas lúdicas a serem desenvolvidas no cotidiano das aulas sendo o fator determinante a proficiência lúdica do docente, ou seja, o educador pode propor novas possibilidades no fazer pedagógico. Este, inegavelmente, deve estruturar as bases da formação inicial e contínua objetivando o domínio do professor sobre os conhecimentos do lúdico em prol da aplicabilidade no cotidiano escolar. O brincar, o jogo, a brincadeira tornar-se 
agradável, essa potente ferramenta facilitadora no processo do ensino e aprendizagem, permite observar que o desenvolvimento está acontecendo no intelectual e no físico do educando com autismo, como também, possibilita mediante sua utilização dinamizar a didática pedagógica.

Finalizo, afirmando não existe uma formula mágica para ensinar uma criança com autismo, mas, existe a formação acadêmica que prepara e qualifica o profissional, para que se torne um investigador, pesquisador, afetuoso e observador para identificar a singularidade humana do educando com espectro do autismo, com isso, proporcionar uma proposta pedagógica que alcance suas especificidades educativas mesmo que o caminho seja um modo diferente de ensinar e um modo diferente de aprender.

Concluo, conforme mencionado no corpo do artigo que a educação inclusiva precisa de uma política educacional comprometida com essa inclusão em sua totalidade com políticas públicas engajadas em promover melhorias para a educação desse alunado, tendo em vista um especialista capacitado para fazer toda diferença na vida estudantil do educando com transtorno do espectro do autismo. Desejo que os frutos desta pesquisa possam alcançar e conscientizar demais profissionais do campo da Educação. 


\section{BIBLIOGRAFIA}

ALMEIDA, M.L.P.; TELLO, C. Consolidando o campo da investigação da política educacional (apresentação). In. TELLO, C.; ALMEIDA, M.L.P. Estudos epistemológicos no campo da pesquisa educacional. Campinas, SP: Mercado das Letras, 2015.

ANTUNES, Celso. Jogos para a estimulação das múltiplas inteligências, 16 ed, Petrópolis: Vozes, 1998.

BARRETO, Elba Siqueira de Sá. Políticas de formação docente para a educação básica no Brasil: embates contemporâneos. Revista Brasileira de Educação, v. 20, n. ${ }^{\circ} 62$ Jul-Set, 2015.

BORGES, Adriana Pereira; NOGUEIRA, Maria L. M. Toda criança pode aprender: o aluno com autismo na escola. $1^{a}$ ed. São Paulo: Mercado de letras, 2018.

BRASIL. Lei de Diretrizes e Bases da Educação Nacional (9.394/1996): promulgada em 20 de dezembro de 1996. Apresentação Carlos Roberto Jamil Cury. 7. Ed. Rio de Janeiro: DP\&A, 2007.

Lei $n^{\circ}$ 12.764, de 27 de Dezembro de 2012. Institui a Política Nacional de Proteção dos Direitos da Pessoa com Transtorno do Espectro Autista; e altera o $\$ 3^{\circ}$ do art. 98 da Lei n. ${ }^{\circ} 8.112$, de 11 de dezembro de 1990. Disponível em http://www.planalto.gov.br/ccivil. Acesso em 15 de Junho de 2020.

Lei $n^{0}$ 13.005, de 25 de Junho de 2014. Aprova o Plano Nacional de Educação e dá outras providências. Disponível em http://planalto.gov.br/ccivil_03/_Ato2011 - 2014/2014/Lei/L13005.htm. Acesso em 05 de Maio de 2020.

Lei $\mathbf{n}^{\mathbf{0}}$ 13.977, de 8 de Janeiro de 2020. Altera a Lei n. ${ }^{\circ} 12.764$, de 27 de dezembro de 2012 (Lei Berenice Piana), e a Lei n. 9.265 , de 12 de fevereiro de 1996, para instituir a Carteira de Identificação da Pessoa com Transtorno do Espectro Autista (Ciptea), e dá outras providências. Disponível em http://www.planalto.gov.br/ccivil_03/_Ato20192022/2020/Lei/L13977.htm. Acesso em 20 de Junho de 2020.

BRITES, Luciana; BRITES, Dr. Clay. Mentes únicas. $2^{a}$ ed. São Paulo: Editora Gente, 2019.

CAMARGOS Jr, Walter et al. Transtornos Invasivos do desenvolvimento: $3^{\circ}$ milênio. $3^{\text {a }}$ Ed. - Brasília: Secretária de Direitos Humanos. Subsecretaria Nacional de Promoção dos Direitos da Pessoa com Deficiência, 2010.

CUNHA, Eugênio. Autismo na escola: um jeito diferente de aprender, um jeito diferente de ensinar. $5^{\mathrm{a}}$ ed. Rio de Janeiro, 2018.

FRANCO, Marcelo Araujo. Ensaio sobre as tecnologias digitais da inteligência. Campinas, SP: Papirus, 1997.

FREIRE, Paulo. Pedagogia da Autonomia: saberes necessários à prática educativa. $51^{\mathrm{a}}$ ed, Rio de Janeiro: Paz e Terra, 2015.

GATTI, Bernardete A. Formação de professores no Brasil: características e problemas. Educ. Soc., Campinas, v. 31, n. 113, p. 1355-1379, out.-dez. 2010. 
GISSI, M. L.; BUCCIO, M. I. Políticas educacionais, formação de professores e inclusão: os desafios da escola da educação básica. In: ENS, R. T. VILLAS BÔAS, L. BEHRENS, M. A. (org.) Espaços Educacionais: das políticas docentes à profissionalização. Curitiba: PUCPRess, 2015.

IMBERNÓN, Franscisco. Formação docente e profissional: formar-se para a mudança e incerteza. $6^{a}$ ed. São Paulo: Cortez, 2006.

OLIVEIRA, Marta Kohl de. Vygotsky: Aprendizado e desenvolvimento um processo sócio-histórico. São Paulo: Scipione, 1997.

KISHIMOTO, Tizuko Morchida. Jogo, Brinquedo, brincadeira e a educação. 14 ed. São Paulo: Cortez, 2011.

TARDIF, Maurice. Saberes docentes e formação profissional. 13. Ed. Petrópolis, RJ: Vozes, 2012.

TELLO, C. MAINARDES, J. Políticas docentes na América Latina: entre o neoliberalismo e o pós-neoliberalismo. In: ENS, R.T. VILLAS BÔAS, L. BEHRENS, M. A. (org.) Espaços Educacionais: das políticas docentes à profissionalização. Curitiba: PUCPRess, 2015. 